\title{
Health Challenges and Perspectives for sub-Saharan Africa
}

Recently, the WHO circulated a note that re-proposes the Nursing Now campaign (2018), which highlighted the fundamental role of the Nurses and Midwives in improving health on a global scale through healthcare, health systems governance and training actions .A few weeks before The Lancet had published the report of the Commission on the future of health in sub-Saharan Africa (2017). There, the situation of sub-Saharan Africa is described with great care and precision: it transpires, in the first place, that such as a history of resource exploitation and colonization has left deep failures in economic and social structures, and that to this day, they heavily affect the health of the populations. The tumultuous growth of the last decade, characterized by a malevolent and clumsy attempt from high-income countries to transfer the global Western system to Africa, has not led to overcoming these failures. But, even if there are signs of improvement, there seems to be a generation of possible conditions for a new 'colonization' camouflaged in the form of a not-betterspecified "aid", and thus the health and safety issues are still major problems and challenges for sub-Saharan Africa. Even today, however, too often the term Global Health is used to repropose as a central issue of the relationships between governments with higher income and those with low and middle income, in particular of Africa, the development of markets or the "interest" of the first to develop such reports, and Science Diplolmacy or international scientific relationship as a key entry to these countries (Gluckman et al 2017). These relationships, on the contrary to be ethically and politically productive, must develop on the basis of equality and mutual satisfaction of governments and populations, especially in the field of health. It is precisely the improvement of health services and systems that will lead to an increase in the quality and the possibility of access to treatment. This is therefore the main ground on which to measure the relationship between Governments The improvement in terms of quality and access to care and the whole organization 
of health services are the real indicators to be used for future evaluation of the effectiveness and appropriateness of supporting actions that will be taken. In this perspective, health is the true and essential ground for diplomatic relations in the coming years (Rubbini 2017). This so not only in the form of the new national health frameworks already present in many countries - from Angola to Namibia, Botswana, Zimbabwe and others (Green 2018) - but also in the ability to give life to consortia of countries with similar needs and conditions that can support each other to deal with the most urgent health and social challenges.

This means community and administrative sharing of hospitals and first- and second-level health facilities, territorial organization of emergencies, facilities for the training of staff and task force for emergencies. To do this the role of nurses and midwives is essential. In Namibia, the awareness of the prospects indicated by the Lancet Commission and by many other documents circulated by the WHO, is being realized, thanks to the new collaboration between the University of Ferrara (Italy) and the Namibian University of Science and Technology. The new initiative in this direction is the creation of a Bachelor's degree in Nursing and Midwifery and a proposal for a national training center as a point of reference for the entire sub-Saharan Africa consortium area. The agreement we are talking about represents, in our view, the ideal point of contact between the situation and the needs set out in the Commission's report and the role of nurses and midwives underlined by the WHO. The role of science and international scientific collaboration must therefore be directed towards the creation of local structures and professional skills that can act as a point of aggregation for supranational interests as it was well identified by the KFPE (2014) (Commission of the Swiss Academy of Science) and we have also been inspired by them. This in particular with regard to those countries with similar health problems. This agreement and the actions deriving from the new Bechelor's Degree for nurses and midwifery with the repercussions that will follow on the 
quality of healthcare in Namibia and, in perspective, in the sub-Saharan area, represent a way of giving practical realization to those principles that abandoning all colonialist intentions are aimed at developing relations between countries on an equal footing and support for local development and ultimately to overcome limits and conditions of life that for too long the colonial era forced upon them.

Compliance with Ethical Standards: This study was not founded

C.o.I. :We do not have any conflict of interest

References:

https://mailchi.mp/who.int/nursing-now?e=147ef00380 ( Accessed April 26,2018)

The Lancet Commissions. The path to longer and healthier lives for all Africans by 2030: the Lancet Commission on the future of health in sub-Saharan Africa. The Lancet, 23 December 2017, Volume 390, No. 10114, p. 2803-2859.

Gluckman PD, Turekian V, Grimes RW, and Kishi T, (2017) "Science Diplomacy: A Pragmatic Perspective from the Inside," Science \& Diplomacy, Vol. 6, No. 4 (http:// www.sciencediplomacy.org/article/2018/pragmatic-perspective ( Accessed April 20.2018)

Rubbini M. (2017) Global health diplomacy: Between global society and neocolonialism: The role and meaning of "ethical lens" in performing the six leadership priorities. Journal of Epidemiology and Global Health.. DOI 10.1016/j.jegh.2017.11.002 (In press).

Green A. (2018) Zimbabwe post-Mugabe era: reconstructing a health system. The Lancet, 06 DOI: http://dx.doi.org/10.1016/S0140-6736(18)30007-2.

A Guide for Transboundary Research Partnerships: 11 Principles (C KFPE 2012 / 2nd edition 2014) 
